\title{
Sigmoid Sinus Dural Arteriovenous Fistula With Spinal Venous Drainage Manifesting as Only Brainstem-Related Neurological Deficits Without Myelopathy
}

\author{
-Case Report- \\ Yasushi Sugiura, Takao NozAKi*, Haruhiko SATO*,
Kouji Sawashita*, Hisaya HiRAMATSU**, and Shigeru NisHizAWA*** \\ Departments of Endovascular Neurosurgery and \\ * Neurosurgery, Seirei Mikatahara Hospital, Hamamatsu, Shizuoka; \\ ${ }^{* *}$ Department of Neurosurgery, Hamamatsu University School of Medicine, \\ Hamamatsu, Shizuoka; \\ *** Department of Neurosurgery, University of Occupational and \\ Environmental Health, Kitakyushu, Fukuoka
}

\begin{abstract}
A 69-year-old woman presented with an extremely rare sigmoid sinus dural arteriovenous fistula (AVF) with venous drainage into a spinal perimedullary vein manifesting only as brainstem dysfunction without myelopathy. Cerebral angiography showed retrograde venous drainage into both the brainstem and spinal cord through the ipsilateral bridging vein from the affected isolated sigmoid sinus. Magnetic resonance (MR) imaging showed a hyperintense lesion in the medulla oblongata and lower pons with increased apparent diffusion coefficient (ADC), and enhancement with contrast material. The dural AVF was successfully treated by transfemoral transvenous embolization from the contralateral side, but the hyperintense area and neurological symptoms persisted after the treatment. The neurological deficits were probably due to venous hypertension associated with accessory retrograde venous drainage into the brainstem. MR imaging enhancement of the lesion may be more closely related to the prognosis of neurological deficits than the ADC value.
\end{abstract}

Key words: sigmoid sinus, dural arteriovenous fistula, brain stem, spinal perimedullary vein, embolization

\section{Introduction}

Cerebral dural arteriovenous fistulas (AVFs) can be classified into five types according to the venous drainage patterns. ${ }^{2)}$ Type $\mathrm{V}$ is defined as cerebral dural AVF with spinal drainage and is quite rare. Only 12 patients with type $\mathrm{V}$ were found among 205 patients with cerebral dural AVFs. ${ }^{2)}$ Only a few cases of the type V dural AVF have been reported, most commonly located in the tentorium cerebelli, foramen magnum, and superior petrosal sinus. ${ }^{2,6,13,14,16,18,19,21)}$ Most patients with type V dural AVF presented with myelopathy, ${ }^{1,6,14,18)}$ whereas neurological deficits based on brainstem disturbance are rare. ${ }^{13,16,19)}$ Type V dural AVF of the trans-

Received February 1, 2008; Accepted September 5, 2008 verse-sigmoid sinus is extremely rare. ${ }^{2)}$

We treated a patient with a sigmoid sinus dural AVF with retrograde venous drainage into the brainstem and spinal cord (type V), manifesting only as neurological deficits due to brainstem disturbance without myelopathy.

\section{Case Report}

A 69-year-old woman suffered left pulsatile tinnitus which gradually subsided 10 days later. Four weeks later, she suddenly suffered onset of nausea, vomiting, and unsteady gait. Neurological examination disclosed horizontal nystagmus, but no other neurological deficits. No cephalic bruit was audible. $\mathrm{T}_{2^{-}}$ weighted or diffusion-weighted magnetic resonance (MR) imaging showed no abnormalities. Ten days after admission, she developed progressive gait distur- 

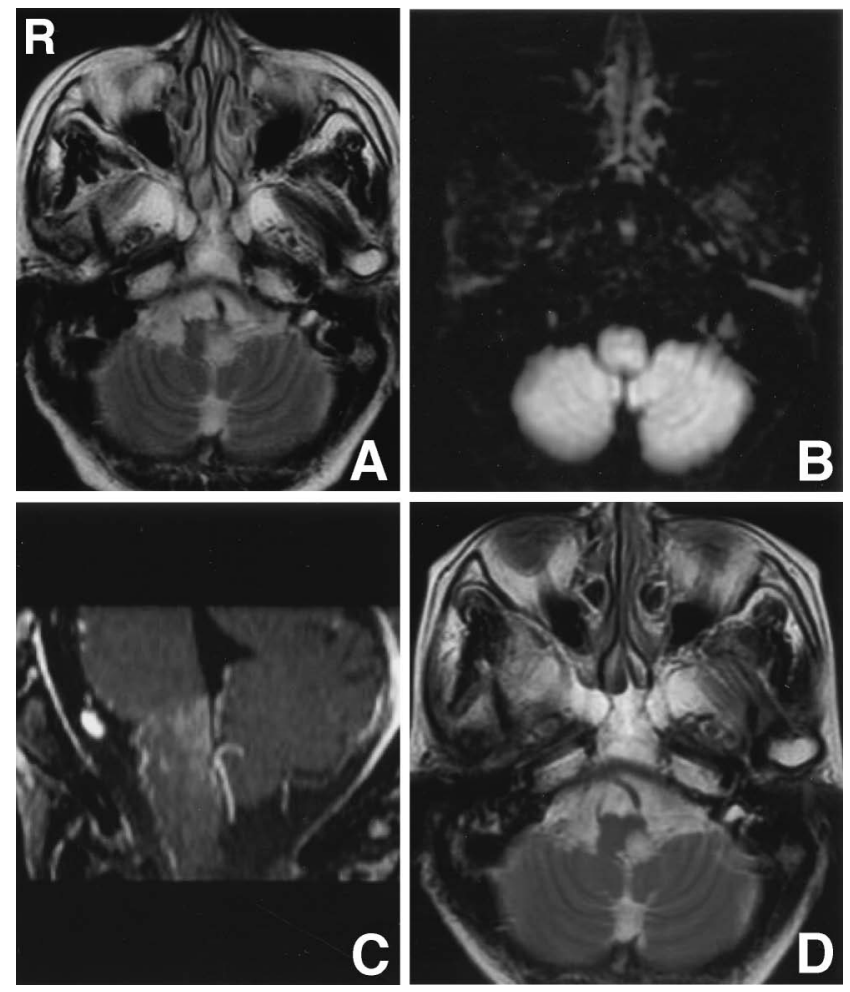

Fig. 1 A: $T_{2}$-weighted magnetic resonance (MR) image showing high intensity areas in the left medulla oblongata. B: Diffusionweighted MR image showing no abnormal intensity area. C: Sagittal $\mathrm{T}_{1}$-weighted MR image with contrast medium of the lower brainstem and cerebellum showing enhancement of the left dorsal surface of the medulla oblongata and abnormal dilated veins around the brainstem. $\quad D: T_{2}$-weighted MR image 3 weeks after embolization showing the same findings as before treatment.

bance, and left ptosis, numbness of the left upper extremity, and swallowing difficulty occurred in the following few days. Neurological examination found sensory disturbance of the right side of the face, mild weakness of the right lower limb, left cerebellar ataxia, and left Horner syndrome. $\mathrm{T}_{2}$-weighted MR imaging showed high intensity areas in the left medulla oblongata and the left dorsal lower pons (Fig. 1A). However, diffusion-weighted MR imaging detected no abnormal high intensity lesion (Fig. 1B). The apparent diffusion coefficient (ADC) was higher $\left(1.01 \times 10^{-3} \mathrm{~mm}^{2} / \mathrm{sec}\right)$ in the left half of the medulla oblongata than in the right half $\left(0.8 \times 10^{-3} \mathrm{~mm}^{2}\right.$ /sec). These high ADC values persisted even 7 weeks after the onset. $\mathrm{T}_{1}$-weighted MR imaging with contrast medium showed enhancement of the left dorsal
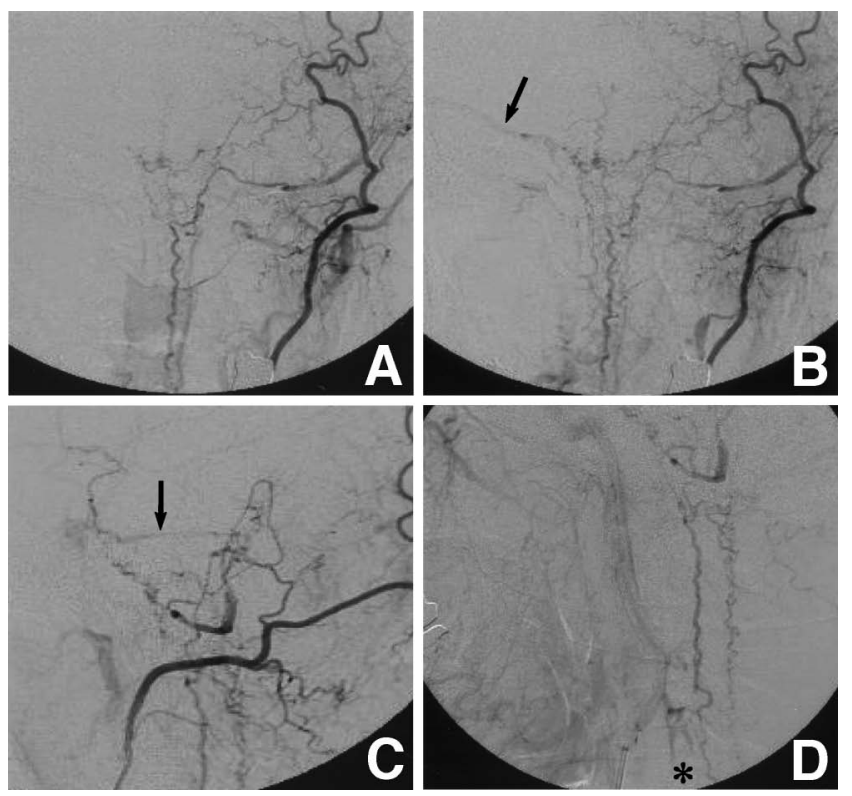

Fig. 2 Left external carotid angiograms, anteroposterior $(A, B)$ and lateral $(C, D)$ views, showing a left sigmoid sinus dural arteriovenous fistula supplied by the transosseous branches of the left occipital artery. The isolated left sigmoid sinus drained into the left lateral medullary vein through the ipsilateral bridging vein at the isolated sinus $(A, B)$. The venous drainage continued through the veins surrounding the brainstem such as the anterior pontomesencephalic vein, and anterior and posterior spinal perimedullary veins (B-D). The drainage ultimately reached the contralateral superior petrosal sinus (B, C: arrows). Asterisk: fourth vertebral level.

surfaces of the medulla oblongata and lower pons, and abnormal dilation of veins around the brainstem (Fig. 1C). Venous congestion caused by some vascular lesion was suspected, and the patient was referred to our department.

Cerebral angiography showed a left sigmoid sinus dural AVF supplied by the transosseous branches of the left occipital artery (Fig. 2). The proximal and distal ends of the left sigmoid sinus were occluded, suggesting isolated sinus. The isolated left sigmoid sinus drained into the left lateral medullary vein through the ipsilateral bridging vein at the isolated sinus. The venous drainage continued through the veins surrounding the brainstem such as the anterior pontomesencephalic vein, and anterior and posterior spinal perimedullary veins. The drainage ultimately reached the contralateral superior petrosal sinus (SPS). Neurological examination and 


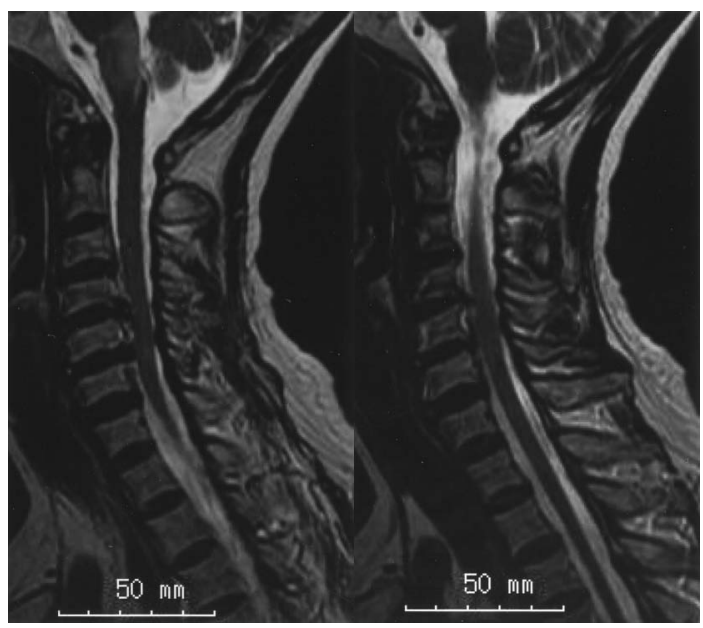

Fig. $3 \mathrm{~T}_{2}$-weighted magnetic resonance images of the cervical spinal cord showing no abnormal intensity or swelling.

MR imaging of the cervical spinal cord (Fig. 3) indicated that the neurological deficits were caused by brainstem disturbance, and not by myelopathy.

The patient underwent transfemoral transvenous embolization of the cerebral dural AVF via the right jugular vein under local anesthesia 2 months after the onset of the brainstem symptoms. The tip of a 4French coaxial guiding catheter (Medikit, Tokyo) was placed at the proximal portion of the left transverse sinus and the tip of a 6-French Envoy guiding catheter (Cordis, Miami, Fla., U.S.A.) at the right jugular bulb. The occluded transverse sinus was penetrated from the proximal side with an Excelsior microcatheter (Boston Scientific, Natick, Mass., U.S.A.), and the catheter was navigated to the distal end of the isolated sinus using a 0.016-inch GT and a 0.014-inch Radifocus guidewire (Terumo, Tokyo) (Fig. 4A). The affected sigmoid sinus was completely packed with Guglielmi detachable coils (Boston Scientific) (Fig. 4B). Angiography performed immediately after embolization showed no contrast filling of the dural AVF (Fig. 4C, D).

Motor weakness of her lower extremity gradually improved after the embolization. However, her limb ataxia, numbness of the right upper extremity, and swallowing difficulty only partially improved and so persisted. $\mathrm{T}_{2}$-weighted $\mathrm{MR}$ imaging showed a hyperintense area in the same location of the medulla oblongata (Fig. 1D), and $\mathrm{T}_{1}$-weighted MR imaging showed the left dorsal surface of the medulla oblongata continued to be enhanced at 3 weeks after the embolization.
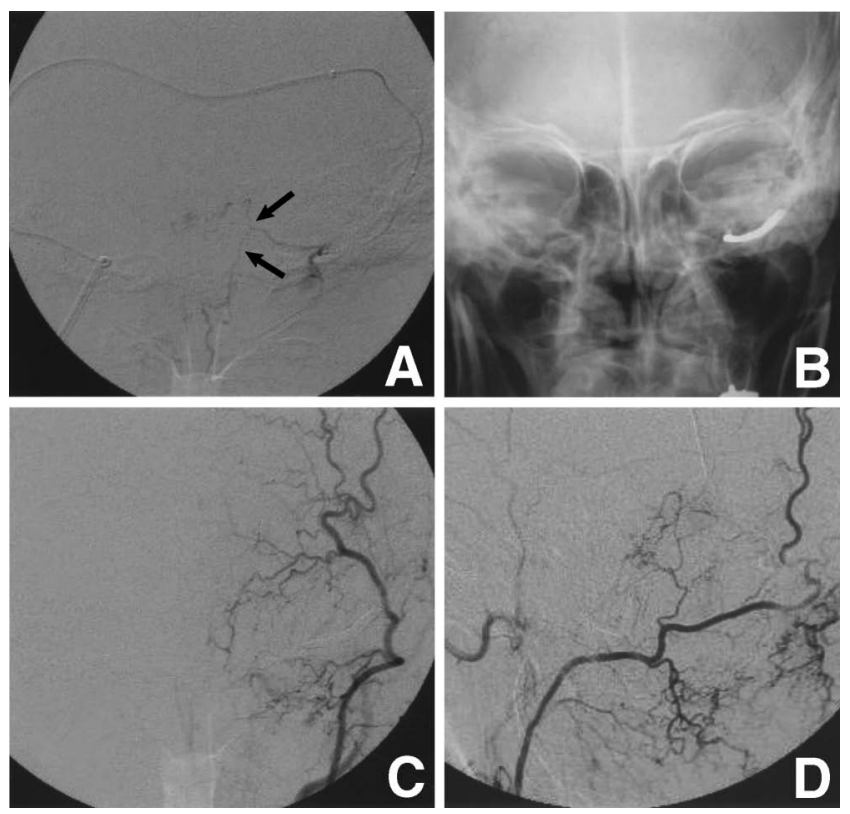

Fig. 4 Radiological findings during embolization. A, B: Anteroposterior sinograms during embolization (A), and after the affected sigmoid sinus was completely packed with Guglielmi detachable coils (B). Arrows: lateral medullary vein. C, D: Left occipital angiograms immediately after embolization, anteroposterior (C) and lateral (D) views, showing no contrast filling of the dural arteriovenous fistula.

\section{Discussion}

Only 6 cases of transverse-sigmoid sinus dural AVFs with venous drainage into the spinal perimedullary vein have been reported.6,14,16,18,19,21) The affected transverse-sigmoid sinuses showed some venous restriction in all cases, and isolated sinus, as in the present case, was observed in 3 cases. ${ }^{6,18,21)}$ The venous drainage descended into the cervical spinal perimedullary veins through the SPS in 2 cases. ${ }^{16,21)}$ However, the drainage patterns were not described in the other 4 cases. ${ }^{6,14,18,19)}$ The venous draining pattern in the present case reached the lateral medullary vein through the bridging vein at the distal end of the isolated sigmoid sinus, and descended into the spinal veins. Such a draining pattern is extremely rare, possibly because the bridging vein is not usually observed. ${ }^{17)}$

The present patient also presented with unusual symptoms of neurological deficits caused by brainstem disturbance, but no symptoms related to myelopathy, despite the presence of venous drainage into the spinal perimedullary veins. 
Table 1 Clinical and imaging characteristics of reported cases presenting with only brainstem dysfunction without myelopathy caused by intracranial dural arteriovenous fistulas with spinal perimedullary venous drainage

\begin{tabular}{|c|c|c|c|c|c|}
\hline Author (Year) & $\begin{array}{l}\text { Patient age } \\
\text { (yrs)/Sex }\end{array}$ & $\begin{array}{l}\text { Location of } \\
\text { fistula }\end{array}$ & Impaired brainstem & Route to spinal veins & Spinal venous drainage \\
\hline $\begin{array}{l}\text { Oishi et al. } \\
\qquad(2005)^{16)}\end{array}$ & $68 / \mathrm{F}$ & transverse sinus & medulla oblongata & $\begin{array}{l}\text { petrosal vein, } \\
\text { anterior pontomesencephalic } \\
\text { vein }\end{array}$ & $\begin{array}{l}\text { anterior and posterior } \\
\text { perimedullary veins }\end{array}$ \\
\hline $\begin{array}{l}\text { Satoh et al. } \\
(2005)^{19)}\end{array}$ & $38 / \mathrm{F}$ & $\begin{array}{l}\text { transverse-sigmoid } \\
\text { sinus }\end{array}$ & medulla oblongata & not described & $\begin{array}{l}\text { posterior perimedullary } \\
\text { vein }\end{array}$ \\
\hline $\begin{array}{l}\text { Lagares et al. } \\
(2007)^{13)}\end{array}$ & $65 / \mathrm{M}$ & torcular herophili & $\begin{array}{l}\text { medulla oblongata, } \\
\text { lower pons }\end{array}$ & $\begin{array}{l}\text { inferior vermian vein, } \\
\text { cerebellar vein, } \\
\text { anterior pontomesencephalic } \\
\quad \text { vein }\end{array}$ & $\begin{array}{l}\text { anterior and posterior } \\
\text { perimedullary veins }\end{array}$ \\
\hline Present case & $69 / \mathrm{F}$ & sigmoid sinus & $\begin{array}{l}\text { medulla oblongata, } \\
\text { lower pons }\end{array}$ & $\begin{array}{l}\text { bridging vein, } \\
\text { lateral medullary vein }\end{array}$ & $\begin{array}{l}\text { anterior and posterior } \\
\text { perimedullary veins }\end{array}$ \\
\hline
\end{tabular}

Cerebral dural AVFs with spinal perimedullary venous drainage generally manifest as symptoms of ascending myelopathy. ${ }^{1,6,14,18,19)}$ Neurological symptoms related with brainstem disturbance only occur in the late phase.1,6,14,19) Only 3 patients presented with only neurological symptoms related to brainstem disturbance and no symptoms caused by myelopathy. ${ }^{13,16,19)}$ Table 1 summarizes the clinical data of those cases and the present case. All 4 patients had symptoms related to disturbance of the medulla oblongata. Three of the 4 patients had retrograde venous drainage into the anterior pontomesencephalic vein, and 3 had remarkable descending spinal venous drainage. Although the exact mechanisms to explain the exclusive occurrence of brainstem symptoms without myelopathy are not clear, brainstem dysfunction may be related to the involvement of the anterior pontomesencephalic vein. ${ }^{13)}$ However, this mechanism cannot explain the absence of myelopathy because dural AVFs with spinal venous drainage frequently show similar venous drainage patterns. ${ }^{1,6,18)}$ Investigation of the relationship between clinical presentation and venous drainage of cerebral dural AVFs with spinal venous drainage found that patients without myelopathy had venous drainage limited to the cervical spinal cord, whereas patients with myelopathy had extensive venous drainage descending forward of the lower thoracic spinal cord. ${ }^{1)}$ Therefore, drainage from perimedullary veins into epidural veins via a medullary-radicular vein at the cervical level might prevent venous hypertension of the spinal cord, resulting in disturbance of the intact spinal cord. ${ }^{1)}$

No precise study of the spinal venous drainage was obtained in any of the 4 cases. Patients with type $\mathrm{V}$ cerebral dural AVFs can have descending venous drainage routes into the spinal perimedullary veins via peri-brainstem veins. ${ }^{1)}$ In contrast, the venous drainage route in the present case descended both into the brainstem and into the spinal cord via the lateral medullary vein, and the venous drainage route reached the contralateral SPS. The presence of accessory venous sinus routes might be related to the clinical presentation in cerebral dural AVFs. ${ }^{8)}$ Consequently, retrograde venous flow and hemodynamic stress are greater in patients with accessory routes, and neurological deficits develop more rapidly. On the other hand, neurological deficits might manifest more slowly in the absence of an accessory route. Therefore, we speculate that venous reversal flow and pressure were greater in our patient because of the accessory route into the SPS. The lateral medullary vein received considerable venous load from the dural AVF, and the venous flow and pressure in the brainstem to the SPS were higher compared with those in the spinal medullary veins, resulting in early development of brainstem disturbance but relatively little effect on the spinal cord. Schemas of venous drainage patterns in the present case and a more common case are shown in Fig. 5.

The prognosis for patients with cerebral dural AVF may be indicated by the MR imaging findings. ${ }^{7,9-11)}$ Obviously, venous hypertension or congestion causes both vasogenic and cytotoxic edema. ${ }^{4,15)}$ Vasogenic edema might be reversible, but not cytotoxic edema. ${ }^{15)}$ Diffusion-weighted MR imaging can differentiate vasogenic and cytogenic edema. ${ }^{7,15,20)}$ Vasogenic edema appears as increased ADC, and cytotoxic edema as decreased ADC value. Enhancement by gadolinium-diethylenetriaminepenta-acetic acid in hyperintense areas on $\mathrm{T}_{2}$ weighted MR imaging may reflect irreversible ischemic changes. ${ }^{9,10)}$ Therefore, both the ADC and the extent of enhancement might be useful for evaluation of the prognosis. In the present case, diffusionweighted MR imaging showed increased ADC before treatment, which is supposed to reflect reversi- 

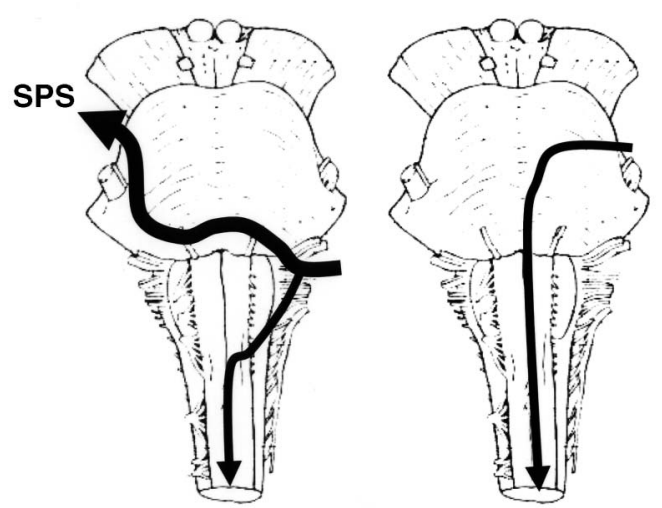

Fig. 5 Schema showing venous drainage patterns in the present case (left) and in a more common case (right) of intracranial dural arteriovenous fistula. SPS: superior petrosal sinus.

ble changes. However, diffuse enhancement was observed around the medulla oblongata, and the hyperintense lesion persisted on $\mathrm{T}_{2}$-weighted $\mathrm{MR}$ imaging after the treatment. Such findings indicate that the neurological deficits might be irreversible. However, the neurological symptoms of our patient persisted despite successful treatment. Therefore, the presence of enhancement may be a more reliable prognostic indicator than the ADC.

Optimal treatments for cerebral dural AVF with isolated transverse-sigmoid sinus remain unclear because of the presence of sinus occlusion or inaccessibility to catheter insertion. ${ }^{5,12)}$ Direct sinus packing with microcoils through a small craniotomy has been proposed. ${ }^{3)}$ In the present case, the proximal segment of the sigmoid sinus was occluded, and the affected sinus was small. Direct puncture was considered to be very difficult because of such anatomical characteristics. Therefore, we adopted the transfemoral, transvenous contralateral approach. This method can have significant benefits for dural AVF associated with isolated sinus. ${ }^{12)}$

\section{References}

1) Brunereau L, Gobin YP, Meder JF, Cognard C, Tubiana JM, Merland JJ: Intracranial dural arteriovenous fistulas with spinal venous drainage: relation between clinical presentation and angiographic findings. AJNR Am J Neuroradiol 17: 1549-1554, 1996

2) Cognard C, Gobin YP, Pierot L, Bailly AL, Houdart E, Casasco A, Chiras J, Merland JJ: Cerebral dural arteriovenous fistulas: Clinical and angiographic corre- lation with a revised classification of venous drainage. Radiology 194: 671-680, 1995

3) Endo S, Kuwayama N, Takaku A, Nishijima M: Direct packing of the isolated sinus in patients with dural arteriovenous fistulas of the transverse-sigmoid sinus. J Neurosurg 88: 449-456, 1998

4) Forbes KP, Pipe JG, Heiserman JE: Evidence for cytotoxic edema in the pathogenesis of cerebral venous infarction. AJNR Am J Neuroradiol 22: 450-455, 2001

5) Gobin YP, Houdart E, Rogopoulos A, Casasco A, Bailly AL, Merland JJ: Percutaneous transvenous embolization through the thrombosed sinus in transverse sinus dural fistula. AJNR Am J Neuroradiol 14: 1102-1105, 1993

6) Gobin YP, Rogopoulos A, Aymard A, Khayata M, Reizine D, Chiras J, Merland JJ: Endovascular treatment of intracranial dural arteriovenous fistulas with spinal perimedullary venous drainage. J Neurosurg 77: 718-723, 1992

7) Inoue $T$, Takahashi $T$, Shimizu $H$, Matsumoto $Y$, Takahashi A, Tominaga T: Congestive myelopathy due to cervical perimedullary arteriovenous fistula evaluated by apparent diffusion coefficient values: case report. Neurol Med Chir (Tokyo) 46: 559-562, 2006

8) Kai Y, Hamada J, Morioka M, Todaka T, Mizuno T, Ushio Y: Pre- and post-treatment MR imaging and single photon emission CT in patients with dural arteriovenous fistulas and retrograde leptomeningeal venous drainage. AJNR Am J Neuroradiol 24: 619-625, 2003

9) Kai Y, Hamada J, Morioka M, Yano S, Ushio Y: Brain stem venous congestion due to dural arteriovenous fistulas of the cavernous sinus. Acta Neurochir (Wien) 146: 1107-1112, 2004

10) Kataoka H, Miyamoto S, Nagata I, Ueba T, Hashimoto $\mathrm{N}$ : Venous congestion is a major cause of neurological deterioration in spinal arteriovenous malformations. Neurosurgery 48: 1224-1230, 2001

11) Kawaguchi T, Kawano T, Kaneko Y, Ooasa T, Tsutsumi M, Ogasawara S: Classification of venous ischemia with MRI. J Clin Neurosci 8(Suppl 1): 82-88, 2001

12) Komiyama $M$, Ishiguro $T$, Matsusaka $Y$, Yasui $T$, Nishio A: Transfemoral, transvenous embolization of dural arteriovenous fistula involving the isolated transverse-sigmoid sinus from the contralateral side. Acta Neurochir (Wien) 144: 1041-1046, 2002

13) Lagares A, Perez-Nunez A, Alday R, Ramos A, Campollo J, Lobato RD: Dural arteriovenous fistula presenting as brainstem ischaemia. Acta Neurochir (Wien) 149: 965-967, 2007

14) Li J, Ezura M, Takahashi A, Yoshimoto T: Intracranial dural arteriovenous fistula with venous reflux to the brainstem and spinal cord mimicking brainstem infarction. Neurol Med Chir (Tokyo) 44: 24-28, 2004

15) Mullins ME, Grant PE, Wang B, Gonzalez RG, Schaefer PW: Parenchymal abnormalities associated with cerebral venous sinus thrombosis: assessment with diffusion-weighted MR imaging. AJNR Am J 
Neuroradiol 25: 1666-1675, 2004

16) Oishi H, Horinaka N, Shimizu T, Ozaki Y, Arai H: [A case of intracranial dural arteriovenous fistula presenting with brainstem infarction]. No Shinkei Geka 33: 1095-1099, 2005 (Jpn, with Eng abstract)

17) Rhoton AL: The posterior fossa veins. Neurosurgery 47(3 Suppl): 69-92, 2000

18) Ricolfi F, Manelfe C, Meder JF, Arrue P, Decq P, Brugieres P, Cognard C, Gaston A: Intracranial dural arteriovenous fistulae with perimedullary venous drainage. Anatomical, clinical and therapeutic consideration. Neuroradiology 41: 803-812, 1999

19) Satoh M, Kuriyama M, Fujiwara T, Tokunaga K, Sugiu K: Brain stem ischemia from intracranial dural arteriovenous fistula: case report. Surg Neurol 64: 341-345, 2005
20) Schaefer PW, Grant PE, Gonzalez RG: Diffusionweighted MR imaging of the brain. Radiology 217: 331-345, 2000

21) Versali PP, D’Aliberti G, Thalamonti G, Branca V, Boccardi E, Collice M: Progressive myelopathy caused by intracranial dural arteriovenous fistula: report of two cases and review of the literature. Neurosurgery 33: 914-919, 1993

Address reprint requests to: Yasushi Sugiura, M.D., Department of Endovascular Neurosurgery, Seirei Mikatahara Hospital, 3453 Mikatabara-cho, Kita-ku, Hamamatsu, Shizuoka 433-8558, Japan.

e-mail: sgur-y@sis.seirei.or.jp 